\title{
O BAILARINO NO BRASIL É UM PROFISSIONAL OU UMA MICROEMPRESA? \\ Discussões acerca da MEI como forma de atuação profissional
}

\section{The dancer in Brazil is a professional or a microenterprise? Discussions about MEI as a way of working}

\author{
Ana Lígia Trindade \\ Patrícia Kayser Vargas Mangan \\ Universidade La Salle - UNILASALLE
}

Resumo: A criação da lei complementar no 128/2008 fez surgir, no Brasil, a figura do Microempreendedor Individual (MEI), com o propósito de possibilitar que diversos profissionais pudessem sair da ilegalidade, adequando-se às legislações federal, estadual e municipal, sobretudo tributária; além de permitir o exercício regular da profissão de diversos trabalhadores autônomos. Este estudo tem como propósito problematizar acerca da necessidade de registro de MEI para exercer atividades profissionais de arte. Discutiremos sobre implicações do registro de MEI para os profissionais das artes, tendo como foco principal o bailarino profissional. Visamos neste artigo iniciar uma análise dos aspectos profissionais importantes para pesquisadores da temática e para os próprios bailarinos profissionais.

Palavras-chave: Bailarino. Profissão. MEl.

Abstract: The creation of Complementary Law no. 128/2008 gives rise in Brazil to the figure of the Individual Microentrepreneur (MEI), with the purpose of enabling the illegality to be eliminated, adapting itself to federal, state and municipal laws, especially taxation; besides allowing the regular exercise of the profession of self-employed workers. This study has the purpose of problematizing the registration of MEI to carry out professional activities of art. We will discuss the implications of MEI registration for arts professionals, focusing on the professional dancer. We aim to initiate an analysis of the important professional aspects for researchers of the subject and for the professional dancers themselves.

Keywords: Dancer. Profession. MEI 
A criação da lei complementar no 128/2008 fez surgir, no Brasil, a figura do Microempreendedor Individual (MEI), com o propósito de possibilitar que diversos profissionais pudessem sair da ilegalidade, adequando-se às legislações federal, estadual e municipal, sobretudo tributária; além de permitir o exercício regular da profissão de diversos trabalhadores autônomos.

Deste modo, este estudo tem como propósito contextualizar acerca da profissão do bailarino, com intenção de esclarecer acerca da necessidade de registro de Micro Empresa Individual - MEI para exercer atividades profissionais de arte. A pesquisa em andamento ${ }^{1}$, da qual emerge este trabalho, está em busca da compreensão da identidade profissional do bailarino no estado do Rio Grande do Sul. Visamos neste artigo iniciar uma análise dos aspectos profissionais importantes

\footnotetext{
1 A pesquisa, em andamento, está sendo realizada com apoio da Coordenação de Aperfeiçoamento de Pessoal de Nível Superior - Brasil (CAPES) - Código de Financiamento 001. - This study was financed in part by the Coordenação de Aperfeiçoamento de Pessoal de Nível Superior - Brasil (CAPES) - Finance Code 001.
}

para este projeto e para demais pesquisadores da temática.

Inicialmente nos parecem pertinentes esclarecimentos acerca do motivo de estudo específico do registro de $\mathrm{MEI}$. Ao realizarmos entrevistas com profissionais bailarinos vinculados a companhias de dança, descobrimos um fato interessante: todos eles tinham registro de Micro Empresa Individual - MEI. Isso porque apenas desta forma conseguiriam concorrer a editais, inscrever projetos em programas de incentivo à cultura, promovidos pelo Estado, nas esferas federal e estadual, e atuarem como bailarinos de Companhias oficiais de dança. Isso nos levou a questionar: afinal, dentro das Companhias, os bailarinos são profissionais ou microempresas? Quais as desvantagens de ser/ter MEl? Por que somente o profissional das artes, para atuar em empresas formais, necessita registro de MEI? Como este profissional passou de bailarino a empresário?

O trabalho artístico é caracterizado pela imagem de flexibilidade e inserido em contexto 
de autoemprego, freelancing e diversas formas atípicas de trabalho. Sendo, geralmente, uma ocupação de tempo parcial, para a qual a educação formal tem valor relativo, de retornos financeiros incertos e grandes distorções salariais, apresentando maiores níveis de subemprego, emprego em tempo parcial e desemprego. O bailarino, por sua vez, é considerado no mercado de trabalho como autônomo. Como não há políticas públicas para as atividades de caráter continuado no campo da cultura no país, e o padrão de fomento à cultura é focado em projetos, o profissional das artes no Brasil sobrevive "de cachê em cachê, de projeto a projeto". A figura de obrigatoriedade de um registro de MEI, como forma de viabilizar a inserção em oportunidades profissionais, vem sendo pouco discutida e precisa ser avaliada tanto quanto a possíveis vantagens, mas, sobretudo, acerca de desvantagens para os profissionais das artes e dos bailarinos em particular.

\section{A arte e o trabalho: 0 artista como trabalhador}

Por excelência, o trabalho artístico é considerado flexível tanto em termos de conteúdo, locais, horários e contratos de trabalho. A instabilidade na condição de trabalho e na carreira do artista é reconhecida historicamente em vários países, incluindo o Brasil.

As profissões artísticas são as mais ambíguas e constituem um desafio à análise teórica das profissões e do trabalho. Cerqueira (2015) esclarece que a dificuldade de se entender 0 artista como trabalhadores deriva da ideologia romântica da criação como algo fora do mundo, tornando as análises com tendências a "privilegiar a obra do artista enquanto criação estética, em prejuízo do processo de trabalho que a elaborou" (p. 2).

Estudos da década de 1980 indicam que, embora os artistas sejam majoritariamente provenientes da classe média e possuam formação superior à da média da população, poucos sobrevivem da arte (FREIDSON; CHAMBOREDON; 
MENGER, 1986). Tal situação parece inalterada, uma vez que, geralmente são obrigados a exercerem outras atividades econômicas para garantirem seu sustento, diferentemente de profissionais de outras áreas, como médicos, engenheiros, advogados. Além disso, Menger (2005 apud Arruda, 2010, p. 57) afirma que:

(...) o mercado capitalista, incerto e instável utiliza o trabalho do artista como modelo de trabalho flexível, uma vez que o artistatrabalhador dificilmente consegue se manter apenas com o resultado de sua criação, precisando dedicar-se a formas multifacetadas de trabalho: o autoemprego, o freelancing, e as diversas formas atípicas de trabalho - trabalho intermitente, trabalho a tempo parcial, multiassalariado.

Em suas pesquisas, Segnini (2006) identifica que a escolha da profissão para os artistas de espetáculo é, geralmente, uma escolha própria, pautada na paixão em exercê-la. A autora também relata, acerca de suas investigações, que esses trabalhadores artistas músicos e bailarinos - estão submetidos à constante incerteza face à garantia do trabalho. No caso de bailarinos, esclarece Segnini (2006), é preciso manter o corpo preparado diariamente e os músicos necessitam realizar um estudo diário com seus instrumentos musicais, mesmo quando estiverem desempregados. Ou seja, artistas são trabalhadores que trabalham diariamente, sem ter a garantia de remuneração.

Conforme

Kronemberger (2016), produtos culturais de grande alcance, competências exigidas dos artistas, inspiração, formação extrema, são critérios que justificam essas atividades como profissões. Entretanto, as profissões artísticas levam a necessidade que se busque um conceito de profissão que "não se baseie em critérios apenas econômicos e de certificações educacionais formais" e que considere "os critérios sociais os principais definidores da posição social desse grupo" (KRONEMBERGER, 2016, p. 12).

Ao analisar a profissionalização dos músicos de Porto Alegre, a pesquisadora Julia da Rosa Simões (2016) aborda em sua tese alguns pontos importantes para que se 
compreendam as ocupações artísticas (2016, p. 17):

(...) é preciso apontar a necessidade de ampliar-se 0 conceito de profissionalização para categorias afastadas das definições ideal-típicas, como é o caso das ocupações artísticas, para que também se possam estudar as formas de autoorganização que tais categorias colocam em prática, bem como sua capacidade de erigir e fazer respeitar barreiras para a entrada em seu campo de atividade, ou suas estratégias no que concerne ao mercado, à concorrência e à liberdade profissional.

Pensar em artistas - sejam eles músicos, bailarinos, atores como profissionais envolve 0 conhecimento de certas especificidades destes ofícios que, conforme Simões (2016), devem levar em consideração que são diversas as competências $\mathrm{e}$ qualidades exigidas pelo trabalho não alienado desempenhado pelo artista.

Baseada em Frederickson e Rooney (1990), Simões (2016, p. 19) considera a música como uma semiprofissão, basicamente por possuir características tanto de ofício quanto de profissão. Frederickson,
Rooney (1990) e Simões (2016) consideram, portanto, que "o sucesso em música poderia ser medido através de habilidades facilmente observáveis, não através de certificação de conhecimento, conforme atestado pelo fato de um diploma não ser pré-requisito para a entrada em orquestras". Os autores concluem que, "em sua ênfase em habilidades observáveis, a música revela sua essencial orientação de ofício: fazer é mais importante do que saber" (p. 19). Analisando as considerações e conclusões apresentadas por Frederickson, Rooney e Simões, claramente reconhecemos situação semelhante com profissionais bailarinos. Os bailarinos, como os músicos, têm sua formação...

(...) baseada num aprendizado de artífice/artesão, ou seja, na "habilidade manifesta de copiar a performance do professor: análises críticas das tradições do ofício são desencorajadas, e consentimento mútuo dos procedimentos é a base na qual uma lealdade é estabelecida. (SIMÕES, 2016, p. 19)

Entretanto, esse não é o caso no ensino formal de dança em que, 
como na música, se procura colocar - seu estudo mais próximo das demais áreas acadêmicas, mas em linhas gerais, segundo Simões (2016), o ensino musical continua dependendo de observação direta e trabalho sob a batuta de um mestre, situação semelhante na dança.

Simões (2016) revela outra situação, acerca dos profissionais músicos, bastante semelhante aos profissionais bailarinos: 0 perfil enquanto empreendedores dedicados a carreiras freelance, ou enquanto trabalhadores independentes de patrões ou instituições. A autora menciona que o "músico seguidamente precisou dividir-se entre várias atividades: instrumentista, compositor, arranjador e, acima de tudo, professor. Em todas, necessitou ser oportunista, no sentido de que desenvolveu a habilidade de perceber oportunidades e tirar vantagem delas" (p. 23).

Em concordância com Simões (2016), Cerqueira (2015, p. 2) afirma que, nas análises do trabalho artístico,
(...) é possível identificar tanto as seduções de um mercado de trabalho não tradicional (valorização da autonomia, da responsabilidade, da criatividade) quanto às ameaças da efemeridade dos empregos (banalização da atipia salarial e respectivos riscos) e da intensidade da concorrência num contexto de grande fragmentação do trabalho e de grande variabilidade das competências exigidas. Diante disso, o próprio indivíduo é chamado a comportarse como empresário da sua própria carreira, portfólio worker, a custo de uma forte individualização do seu sistema pessoal de atividade.

A autora esclarece que seus estudos acerca do trabalho artístico, baseados em autores como Menger (2005), Segnini (2006) e Benhamou (2007), permitem afirmar que o trabalho artístico é caracterizado pela imagem de flexibilidade e inserido em contexto de autoemprego, freelancing e diversas formas atípicas de trabalho (intermitência, tempo parcial, multi-assalariado).

\section{Mercado de trabalho em dança}

Para o profissional de dança com interesse na atuação cênica e não acadêmica o campo não parece 
muito promissor. Nacht (2009, p. 12) afirma:

Nacht (2009, p. 15), em seu estudo realizado em 2009, aponta os

Infelizmente, o mercado de trabalho brasileiro, (...), é composto por uma maioria expressiva de companhias enquadradas na realidade da instabilidade de recursos, cujas atividades da equipe são caracterizadas pela contínua busca por captação de recursos, enfrentando os desafios da descontinuidade. (...) a maioria das companhias não possui patrocinador estável, grande parte das oportunidades de trabalho para bailarinos não oferece vínculo empregatício ou contrato, pois os artistas são chamados para participar de um projeto com duração específica e, devido ao baixo valor destinado à maioria dos patrocínios culturais, as companhias não conseguem arcar com os pesados encargos atrelados à carteira assinada.

As consequências deste cenário são:

- a atuação free-lancer dos bailarinos, com dependência de cachês inconstantes e com valores oscilantes, fazendo com que estes profissionais não se fixem em uma só companhia/grupo;

- o desafio dos gestores de desenvolverem e estreitarem laços entre os membros da equipe para elaboração de um trabalho de maior nível de qualidade. tipos de companhia/grupo existentes no Brasil, com os modelos mais comuns de organograma:

- Companhia/Grupo - projeto independente: a dimensão da equipe varia de companhia a companhia, podendo ser composta até mesmo por apenas um elemento (coreógrafo/intérprete), mas o formato mais comum é: um coreógrafo/gestor/fundador e os bailarinos free-lancers. Algumas iniciativas possuem ainda ensaiador/professor, que auxilia nas atividades cotidianas e diminuem a carga de trabalho do fundador. A maioria não possui na equipe um profissional especializado no ramo administrativo ou financeiro, e normalmente possuem um produtor também free-lancer que auxilia na realização de apresentações/temporadas.

Inúmeras trabalham diariamente (quantidade de horas varia em função dos compromissos, por vezes de fora da área da dança), e outras agendam ensaios intermitentes, em 
há emprego". Entretanto, a autora discorre:

Ao nos questionarmos acerca do depois da universidade, é necessário cautela para que não formulemos perguntas modernas para respostas contemporâneas. Homens modernos empregam sua criatividade na configuração de ações que se darão em um espaço já determinado de antemão; procuram portanto uma vaga. São estes homens que hoje não têm função. Por outro lado, aqueles que aprenderem rapidamente a habitar o tempo, ou seja, a constituírem suas ações em uma temporalidade contínua e semovente, saberão inventar um seu lugar: estes são homens contemporâneos de sua própria contemporaneidade. A crise do lugar é contemporânea do tempo que surge como entidade definidora da função. (ROCHA, 2010, p. 101)

O predomínio da intermitência como forma de emprego do artista, e particularmente do bailarino, para Neves (2010), assumiu dimensões mais amplas e definitivas no contexto da globalização, no qual o aumento e a normatização de vínculos temporários e precários no mercado têm modificado a organização de trabalho e de produção na sociedade contemporânea. Estes bailarinos contemporâneos estão cada vez mais submetidos às condições de trabalho instáveis oferecidas nesse mercado. Neves esclarece que os espaços de atuação para estes artistas ainda são limitados e o que prevalece no meio é o emprego informal. Em resumo, o bailarino é alvo de vínculos profissionais flexíveis e temporários. As companhias de dança profissionais, que antes proporcionavam condições estáveis de trabalho no Brasil, não escaparam às dinâmicas do mercado.

\begin{abstract}
E o bailarino para continuar no ofício tem que se desdobrar para compensar, com retorno de bilheteria, os contratempos na obtenção de verbas que dependem de leis de incentivo e da subvenção estatal que mantêm esses grupos. Mesmo nas companhias patrocinadas pelo Estado, 0 bailarino enfrenta situação de instabilidade. (NEVES, 2010, p. 136)
\end{abstract}

Essa realidade leva o bailarino a ter que recorrer à utilização máxima do corpo para a sobrevivência do meio. Neves exemplifica esta situação com a Cisne Negro Cia. de Dança de São Paulo, que apresenta em média setenta espetáculos por ano, e em 
2008 superou as expectativas com noventa e quatro apresentações.

Neves (2010, p. 139) acredita que "as formas flexíveis de emprego e o espaço limitado de ocupações estáveis que caracterizam o mercado contemporâneo da dança devem ser problematizados de acordo com a formação e a qualificação profissional dos bailarinos".

De um lado, as possibilidades de contrato estável para esses profissionais são oferecidas nas companhias de dança "privadas", que se mantêm com o mecenato do Estado e com parceria e permutas de empresas (...). Contudo, parte dessas companhias não garante mais empregos formai aos bailarinos, que passaram a ter de se submeter a contratos temporários, de curta duração, que podem ou não ser renovados de acordo com a direção desses grupos. Isso significa dizer que apesar dos salários fixos, os direitos trabalhistas não são obtidos, embora parte dele seja assegurada por meio de tratos verbais. (NEVES, 2010, p. 139)

De qualquer forma, estes vínculos são considerados pelos bailarinos como estáveis. São reconhecidos, embora suas condições informais evidentes, como uma estabilidade "relativa", pois os profissionais recebem por mês, têm jornada fixa de trabalho, não têm custos com a manutenção e a formação continuada do corpo e são protegidos por uma estrutura que pode suprir parte dos direitos do trabalhador. Enfim, o bailarino sobrevive "de cachê em cachê, de projeto a projeto, e o valor dos salários recebidos, de modo irregular, é não só irrelevante como desproporcional ao tempo e ao trabalho despendido nos grupos e companhias" (NEVES, 2010, p. 141142).

\section{Carreira e mercado de trabalho contemporâneo}

O mercado de trabalho contemporâneo se caracteriza principalmente por seu dinamismo, trazendo relevantes mudanças nas carreiras ao longo das últimas décadas, com profundas implicações para os indivíduos, organizações e sociedade. Baruch (2004 apud NACHT, 2009) propõe que uma das questões mais pertinentes neste processo de mudança, consiste na migração do padrão de carreiras 
lineares - estáticas e rígidas - para carreira multidirecionais - dinâmicas e fluidas. E esta mudança pode ser encontrada com várias denominações, como "racionalização", "downsizing", "achatamento", "reestruturação", e até mesmo "se preparar para o futuro".

Desta forma, o antigo sistema de emprego seguro, válido para toda a vida, com previsibilidade de ascensão e estabilidade financeira, está simplesmente morto, gerando um novo acordo de trabalho que coloca a relação entre empregado e empregador como uma constante negociação aberta, baseada no poder do mercado (CAPPELLI, 1999 apud NACHT, 2009).

Baruch (2004 apud NACHT, 2009) sustenta que, após a Revolução Industrial, as empresas desenvolveram e determinaram aos seus funcionários modelos claros e previsíveis de evolução da carreira ao longo dos anos, organizadas de forma hierárquicas, extremamente estruturadas e inflexíveis. Contudo, a partir do ano 2000, devido ao contínuo progresso tecnológico que caracterizou as décadas anteriores, demandando novas vocações e habilidades, esta dinâmica se modificou, resultando na passagem da responsabilidade pela condução da carreira para as mãos dos próprios indivíduos.

Inicia-se no século XXI, segundo Baruch (2004 apud NACHT, 2009), a transferência de relações de trabalho de longo prazo, em que as pessoas buscavam servir à sua empresa ao longo de toda a vida, para relações transitórias e transacionais, nas quais os profissionais esperam que a organização os sirva ao longo dos, possivelmente poucos, anos que durar a relação de trabalho entre as partes. Desta forma, não é mais possível prever o caminho de desenvolvimento da carreira, devido à extensa gama de opções e direções possíveis para esta evolução.

Esta realidade de mercado não se configura em uma novidade para os profissionais da dança no Brasil. Dificilmente o bailarino se encontrava em situação de ter uma organização, seja particular ou governamental, 
responsável pela evolução de sua carreira.

Ainda hoje, no Brasil, não há políticas públicas para as atividades de caráter continuado no campo da cultura, o padrão de fomento à cultura é focado em projetos. Desta forma, na ausência de políticas que permitam um horizonte de trabalho de médio e/ou longo prazo, os eventos calendarizados ${ }^{2}$, espaços culturais independentes e grupos e coletivos artísticos possuem dinâmicas instáveis que prejudicam a qualidade dos profissionais das artes, assim como o resultado de suas atividades (BRASIL, 2016). Como afirmou Neves (2010, p. 141), o bailarino acaba sobrevivendo "de cachê em cachê, de projeto a projeto". No Brasil, esta situação ocorre hoje com toda a área das artes. Atores, músicos, bailarinos, etc. dependem de programas de incentivo à cultura, promovidos pelo

${ }^{2}$ Entende-se por eventos calendarizados as iniciativas organizadas por pessoas jurídicas, com temática cultural específica ou diversificada, sob forma de bienais, colóquios, conferências, congressos, convenções, encontros, feiras, festivais, fóruns, jornadas, mostras, painéis, salões, seminários, simpósios, e similares (BRASIL, 2016, p. 13).
Estado, nas esferas federal e estadual.

Constata-se historicamente, e podemos observar isso também neste estudo, que o profissional da dança sempre teve em suas mãos a condução de sua carreira. Entretanto, esta mudança no mercado também influencia este profissional, refletindo na evolução da carreira e construção de identidade profissional.

\section{MEI e o "paradoxo de Mozart"}

Diante de todo este contexto profissional, de fato, invariavelmente os profissionais da arte se defrontam com o que Bendassolli e Wood Jr. (2010) denominaram "paradoxo de Mozart"3:

\begin{abstract}
Wolfgang Amadeus Mozart foi um pioneiro. Em 1781, o músico deixou os serviços do Arcebispo de Salzburg para tentar a sorte como músico e professor autônomo em Viena. Por 10 anos, Mozart conheceu as alegrias e as
\end{abstract}

3 Por um lado o sonho de liberdade de criação e de autonomia profissional, e por outro a necessidade de encantar a audiência e convencer consumidores a comprarem seus produtos foi denominado "paradoxo de Mozart" por Pedro F. Bendassolli e Thomaz Wood Jr. em 2010. 
tristezas da vida de profissional independente. Para facilitar a venda de suas peças, Mozart ressaltava a flexibilidade das composições, que poderiam ser utilizadas por diversas formações. Sempre que iniciava uma composição ou preparava-se para apresentá-la em público, vinham à tona as questões: como compor para este novo público dos concertos? O que fazer para agradá-los? Mozart morreu em 1791, com 35 anos de idade, endividado, derrotado e marcado pela sensação de fracasso social e profissional. (ELIAS, 1994 apud BEndassolli; Wood Jr., 2010 p. 260)

Ou seja, trata-se do sonho da liberdade de criação e da autonomia profissional, porém condicionado pela necessidade de encantar a audiência e convencer consumidores a comprarem seus produtos, além da administração de sua vida financeira. Desta forma, os artistas buscam a “auto-realização e a autonomia de expressão, porém são limitados pela capacidade de comercializar de forma bem sucedida seus talentos e competências" (BEndassolli, 2009, p. 10). Os autores afirmam que as transformações econômicas, sociais e culturais ocorridas desde os anos 1980 acabaram por colocar profissionais dos mais variados setores diante deste paradoxo.
Entretanto, nem todos os profissionais artistas têm a habilidade de administração da própria carreira. Os profissionais bailarinos, por exemplo, geralmente sofrem com a falta de planejamento de suas carreiras, desinteresse em desenvolver suas qualidades administrativas, dificuldade de identificar seus direitos e deveres e, principalmente, a falta de habilidade com números.

Encontramos a grave situação descrita acima dentro do ambiente de atuação dos bailarinos no Rio Grande do Sul, principalmente nas Cias. Municipais de Dança. Ao analisarmos o edital de $2017^{4}$ para seleção de bailarinos para a Companhia Municipal de Dança de Porto Alegre, encontramos uma relação de documentos a serem apresentados para inscrição. Entre eles aparece o item 2.4.1, sobre a necessidade de 0 candidato ter Contrato Social ou Estatuto ou Certificado MEI (Micro Empresa Individual) com finalidade cultural.

\footnotetext{
${ }^{4}$ Disponível em:

http://www2.portoalegre.rs.gov.br/smc/default .php?reg=548\&p_secao $=184$ Acesso em: 10 mar. 2018.
} 
Verificou-se que os bailarinos do elenco apresentaram um registro de MEl.

A criação da lei complementar no 128/2008 fez surgir, no Brasil, a figura do Microempreendedor Individual (MEI), com o propósito de possibilitar que diversos profissionais pudessem sair da ilegalidade, adequando-se às legislações federal, estadual e municipal, sobretudo tributária; além de permitir o exercício regular da profissão de diversos trabalhadores autônomos. O MEI é uma forma de regularização de quem trabalha por conta própria ou é empreendedor. Sendo microempreendedor individual, é possível ter CNPJ, emitir notas fiscais e contribuir para a aposentadoria. A mídia e os órgãos governamentais procuram divulgar as vantagens do $\mathrm{MEI}$, porém acabam não informando os enormes desafios que ela oferece, principalmente para quem não está acostumado às atividades de contabilidade e administração de empresas.

Portanto, MEI é um profissional autônomo legalizado como pessoa jurídica para empreender em sua atividade econômica, categoria criada para tentar diminuir o número de trabalhadores que atuavam na informalidade. Nesse sentido, a formalização como MEI oferece algumas "vantagens": CNPJ próprio, a conta bancária de pessoa jurídica, possibilidade de emissão de nota fiscal, tributação pelo SIMPLES, contratação de até um empregado recebendo um salário mínimo ou o piso de sua categoria.

Por outro lado, conforme Cardozo e Pieniz (2016, p. 21):

A maior dificuldade percebida nesses empreendimentos é que muitos, ou quase nenhum, possui um controle de caixa eficaz para melhor ajuda-los a gerenciar a situação financeira da empresa. Não tendo conhecimento de sua capacidade das entradas e saídas de recursos, os mesmos não possuíam nenhum tipo de controle de pagamento e recebimento ou simplesmente acabam fazendo anotações informais.

Bailarinos com registro de $\mathrm{MEI}$ têm obrigações e tributos, precisam pagar impostos. Ele paga um valor fixo mensal de acordo com a sua atividade. Se o mês for extremamente ruim para ele e não tiver renda, ainda assim, como $\mathrm{MEI}$, 
ele precisa pagar o valor relativo à sua contribuição mensal. Se não o fizer, terá que arcar com multas e juros. Ele terá um custo alto para fechar ou alterar custos da empresa: enquanto que para formalizar-se ele não paga nada, se quiser encerrar suas atividades, pagará taxas maiores do que empresas com outro regime de tributação. $\mathrm{O} \mathrm{MEI}$ não precisa de contador, então, as obrigações ficam todas sob a responsabilidade do profissional. Todo microempreendedor individual deve seguir uma rotina mensal para se manter regularizado, preenchendo um relatório mensal de receitas e realizando o pagamento da DASNMEI. Anualmente, o MEl também é obrigado a entregar a Declaração Anual Simplificada, que consolida as informações de faturamento, e declarar imposto de renda de pessoa jurídica. Não esquecendo que deverá declarar imposto de renda de pessoa física igualmente. Como $\mathrm{MEI}$, o bailarino também não se aposenta por tempo de contribuição, isso só ocorre se tiver experiência anterior como CLT e contribuir separadamente com 0 prazo restante, o direito a aposentadoria é somente em casos de morte e invalidez, sendo que o valor da aposentadoria é de apenas um salário mínimo.

Em resumo, hoje em dia, se faz necessário aos artistas não somente o DRT, mas também um CNPJ. E o bailarino deve se tornar um pequeno empresário de si mesmo e seu nome artístico deve se tornar um nome fantasia de uma microempresa individual. Entretanto, são poucas as funções na área de arte e cultura que estão elencadas na lista de ocupações permitidas para $\mathrm{MEI}$. Bailarino, por exemplo, não existe. Neste sentido, o ator Alberto de Avyz (2011) comenta em um blog da área da cultura:

Ao analisar o meio por onde o trabalhador pode se tornar 'empresa pessoal', deparei-me com alguns dissabores enquanto artista; poucas funções na área de arte e cultura estavam elencadas. Estaríamos nós, artistas e realizadores culturais, fadados ao eterno anonimato funcional/trabalhista? E depareime com uma das questões mais discutidas desde a criação do MEI e seu cruzamento com os meios culturais (...). 
Existe ainda uma regra do $\mathrm{MEI}$ que estabelece que o empreendedor individual é a pessoa que trabalha por conta própria e que se legaliza como pequeno empresário; NÃO é permitido que um vínculo empregatício (emprego com carteira assinada) seja substituído pela condição $\mathrm{MEI}$, portanto o $\mathrm{MEI}$ não é e nem pode ser um empregado formal de uma empresa, situações que comprovem vínculo empregatício são proibidas.

Avyz (2011) questiona:

(...) porque é que as produtoras e companhias teatrais não dão o devido 'crédito trabalhista' para quem lhes presta serviços diretamente como 'funcionário dentro de um trabalho, mesmo que sazonal'? Aí entram todas aquelas siglas e letras que todo empresário brasileiro sabe o que são e chora por justamente saber o que são. Neste ponto é que se deveria mudar a questão trabalhista do artista. Em vez de tentar enquadrar aqui ou fugir de lá, dever-se-ia sim haver a criação de mais uma figura jurídica, específica para o artista e/ou empresa que trabalha diretamente com este. (...) há esta lacuna, de uma Pessoa Jurídica de cunho Cultural, que não facilite, mas AGILIZE as questões trabalhistas para a classe artística brasileira, esta lacuna AINDA existe.
Martins (2015, p. 56) conclui, em seu estudo sobre as vantagens e desvantagens do MEI, que "é uma ótima oportunidade para a profissionalização de trabalhadores e progressão nas atividades $\mathrm{e}$ negócios, que para tanto, cabe considerar a importância da orientação aos empresários informais". Aparentemente uma grande possibilidade para 0 profissional artista. Já que, atualmente, os artistas precisam comercializar seu talento criativo para conseguirem ser incluídos na produção artística. Ou seja, eles têm que se envolver com pessoas que têm potencial de oferecer oportunidades de trabalho. Este antagonismo arte-comércio exige do artista uma integração de motivação pelo trabalho artístico e entendimento das lógicas econômicas e preocupações sobre um valor de mercado. Entretanto, talvez 0 grande engano seja considerar a arte apenas como um negócio e um artista somente como um empresário.

Recebido em 14/09

Aceito em 18/10/2018 


\section{Referências Bibliográficas}

ARRUDA, Carmen Lúcia Rodrigues. Produção artística na universidade: relações de trabalho do professorartista na UNICAMP. Comunicações, Piracicaba, v. 17, n. 2, p. 51-64, jul./dez. 2010.

AVYZ, Alberto. O MEI, o ator e o humorista. Cultura Digital, 28 maio $2011 . \quad$ Disponível em: http://culturadigital.br/deavyz/2011/05 /28/meihumorista/ Acesso em: 14 ago. 2018.

BARUCH, Y. Transforming career: from linear to multidirectional career paths - organizational and individual perspectives. Career Development International, v. 9, n. 1, p. 58-73, 2004.

BENDASSOLLI, Pedro F. Significado do trabalho e carreira artística: relatório 28/2009. [S.I.]: FGV, 2009. Disponível em: <https://bibliotecadigital.fgv.br/dspac e/bitstream/handle/10438/13434/Ped ro\%20Bendassollinpp relat\%C3\%B3 rio\%20final_p3.pdf?sequence=1\&isAl lowed=y> Acesso em: 20 dez. 2017.

BENDASSOLLI, Pedro F.; Wood Jr., Thomaz. O paradoxo de Mozart: carreiras nas indústrias criativas. o\&s, Salvador, v. 17 , n. 53 , p. 259277, abr./jun. 2010.

BENHAMOU, Françoise. A economia da cultura. São Paulo: Ateliê Editorial, 2007.

BRASIL. MINISTÉRIO DA CULTURA. FUNDAÇÃO
Nacional das Artes - relatório de atividades: março de 2015 a maio de 2016. Brasília: FUNARTE, 2016.

CAPPELLI, P. The new Del at work. Boston: Harvard Business School Press, 1999.

CARDOZO, Sabrina; PIENIZ, Luciana Paim. Gestão para Microempreendedores Individuais - MEl: Fluxo De Caixa Como Aliado. 2016. Disponível em: <https://home.unicruz.edu.br/wpcontent/uploads/2016/09/GestaoPara-MicroempreendedoresIndividuais- -MEI-Fluxo-De-CaixaComo-Aliado.pdf> Acesso em: 14 ago. 2018.

CERQUEIRA, Amanda P. Coutinho de. O artista como trabalhador. In: Colóquio Internacional Marx e Engels, 8., 2015, Campinas. Anais. Campinas: UNICAMP, 2015. Disponível em: $<$ https://www.ifch.unicamp.br/formula rio_cemarx/selecao/2015/> Acesso em: 28 jun. 2017.

FREDERICKSON, Jon; ROONEY, James F. How the Music Occupation Failed to Become a Profession. International Review of the Aesthetics and Sociology of Music, v. 21, n. 2, dez. 1990.

FREIDSON, Eliot; CHAMBOREDON, Jean-Claude; MENGER, PierreMichel. Les professions artistiques comme défi à l'analyse sociologique. Revue française de sociologie, $v$. 27, n. 27-3, p. 431-443, 1986.

NACIONALDE ARTES. Política 
KRONEMBERGER,

Gabriela

Almeida. Profissão e performance: um estudo de caso sobre músicos de orquestra. Revista Música Hodie, Goiânia, v. 16, n. 2, p. 10-24, 2016.

MARTINS, Carliria Amarante. Vantagens e desafios enfrentados pelo microempreendedor individual. 67 f. 2015. Trabalho de Conclusão de Curso (Graduação em Ciências Contábeis) - Centro Universitário Municipal de São José, São José, 2015.

MENGER, Pierre-Michel. Retrato do artista enquanto trabalhador: metamorfoses do capitalismo. Lisboa: Roma, 2005.

MOREIRA, Rui. Encontros setoriais da dança. In: BRASIL. MINISTÉRIO DA CULTURA. FUNDAÇÃO NACIONAL DE ARTES. Política Nacional das Artes - relatório de atividades: março de 2015 a maio de 2016. Brasília: FUNARTE, 2016. p. 76-8.

NACHT, Antonia Kjellerup. A profissão de bailarino na cidade do Rio de Janeiro: mercado de trabalho, relações profissionais, decisões de carreira e identidade profissional. 148f. 2009. Dissertação (Mestrado em Administração) Pontifícia Universidade Católica do Rio de Janeiro, Rio de Janeiro, 2009. Rio de Janeiro: PUC-RJ, 2009.

NEVES, Juliana Cunha Lima. Entre o ar e o chão: metier de bailarino na cidade de São Paulo. 296 f., 2010. Tese (Doutorado em Sociologia) Universidade de São Paulo, Faculdade de Filosofia, Letras e
Ciências Humanas. São Paulo: USP, 2010.

NUSSBAUMER, Gisele; Botelho, Isaura. Políticas culturais para as artes. 2017. Disponível em: <https://portalseer.ufba.br/index.php/ pculturais/announcement/view/158> Acesso em: 07 jul. 2017.

ROCHA, Thereza. A dança depois da universidade: e agora? In: Tomazzoni, Airton; Wosniak, Cristiane; Marinho, Nirvana (orgs.). Algumas perguntas sobre dança $e$ educação. Joinville: Nova Letra, 2010. p. 93-103.

SEGNINI, Marina Petrilli. Prazer e sofrimento no trabalho artístico. In: CONGRESSO INTERNACIONAL DE PSICOPATOLOGIA

FUNDAMENTAL, 2., 2006, Pará. Anais: trabalhos completos. Pará: Universidade Federal do Pará, 2006. Disponível em: $<$ http://www.psicopatologiafundament al.org/uploads/files/ii_congresso_inte rnacional/temas livres/ii con. prazer e_sofrimento_no_trabalho_artistico tl.pdf> Acesso em: 28 jun. 2017.

SIMÕES, Julia da Rosa. Na pauta da lei: trabalho, organização sindical e luta por direitos entre músicos porto-alegrenses (1934-1963). $224 f$. 2016. Tese (Doutorado em História) - Universidade Federal do Rio Grande do Sul, 2016. Porto Alegre: UFRGS, 2016.

STRAZZACAPPA, Márcia. O ensino de dança: dos cursos livres à universidade. In: STRAZZACAPPA, Márcia; MORANDI, Carla. Entre a arte e a docência: a formação do 
artista da dança. Campinas: Papirus, 2006. p. 11-14. 
Moringa Artes do Espetáculo, João Pessoa, UFPB, v. 10 n. 1, jan-jun/2019, p. 29 a 48

\section{moringa}

